\title{
Genetics, genetic testing and sports: Aspects from sports cardiology
}

\author{
HERBERT LÖLLGEN AND RUTH LÖLLGEN ${ }^{1}$
}

\begin{abstract}
There is a major trade-off between improvements in longevity, general health, fitness and quality of life due to regular intense physical activity on the one hand and possible cardiac risks on the other hand, whether for participants in leisure time sports activities or for highly trained athletes. Cardiac complications and sudden death in sports, even though rare, but dramatic, events, are mainly observed in those suffering from inherited, often latent diseases with a strong genetic background, unknown to the subjects. Sedentary lifestyle together with more than one risk factor may also contribute to cardiac events in persons beginning to exercise for the first time or recommencing intense physical activities after a long pause.
\end{abstract}

Manifestations of inherited cardiac diseases with a typical genetic component may occur in children or adolescents, but also in adults. For many inherited cardiac diseases there is a large body of knowledge on the genetic origin, therefore, genetic testing may be a valuable tool for diagnosis and prevention of underlying diseases, especially as genetic testing has become much cheaper over the last few years.

The present paper describes cardiac diseases with genetic disposition and related genetic testing and presents recommendations for genetic examinations. Testing should be of benefit for sportsmen and women but also for family members to prevent fatal cardiac events. These recommendations will consider benefits for the sports person, and ethical reflections as well.

\section{Introduction}

There is a large body of literature indicating that regular physical activity is of benefit to healthy people ${ }^{2}$ as well as those with diseases. ${ }^{3,4}$ Motivation to engage in regular activity can be difficult to achieve in patients and elderly persons. Commencing a programme of physical activity may be further complicated by an increased risk of cardiovascular events, ${ }^{5,6}$ especially if the physical activity is intensive, but even if it is only moderate. This is due to underlying cardiovascular risk factors or due to latent and undetected diseases of genetic origin.

Studies have examined sudden cardiac arrest and even death in highly trained younger or older athletes, also observed in leisure time physical activity. ${ }^{7}$ It is generally assumed that these trained athletes, showing no signs or symptoms, are healthy. However, some inherited diseases may cause greater susceptibility for sudden cardiac emergencies, sometimes not detected in pre-participation examination. ${ }^{8,9,10}$ In many of these diseases, genetic analysis is appropriate to detect and identify the underlying mechanisms of the fatal event. The cardiac arrest in these fatal events is a combination of triggers for arrhythmias, underlying cardiac disease and/or unstable 
electrophysiological substrates due to either hidden "electrical" or heart muscle disease. ${ }^{11,12,13}$

\section{Table 1: Inherited Cardiac Diseases with Genetic Causes}

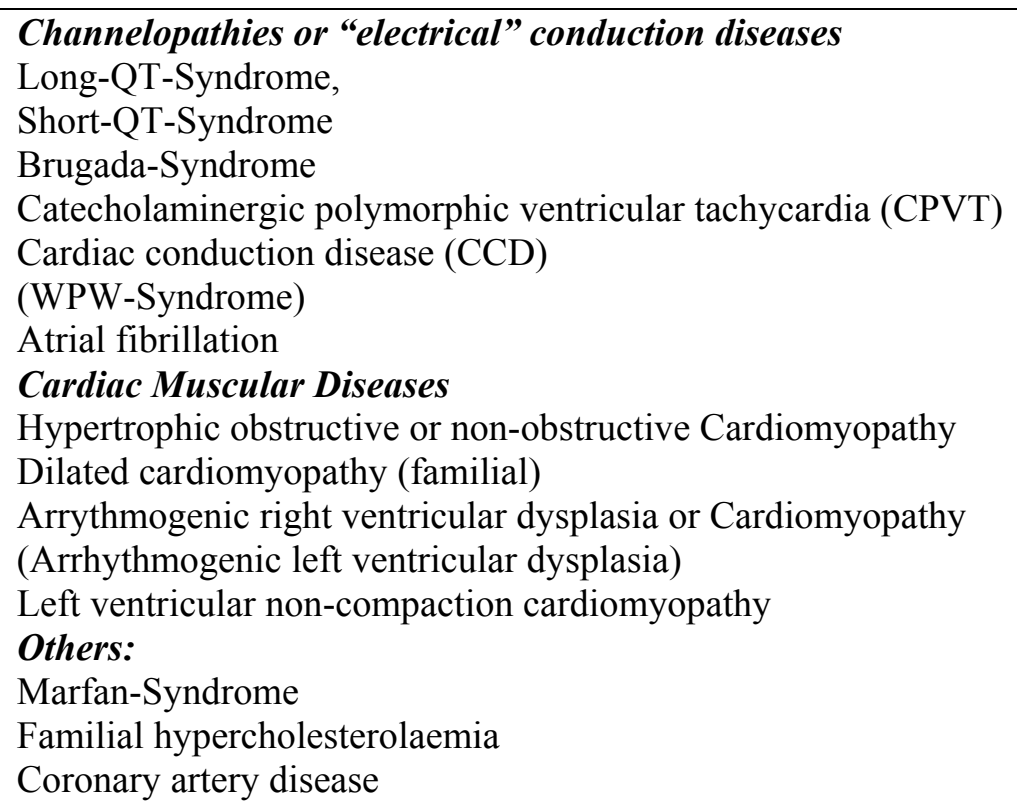

Guidelines for genetic testing are presented as a part of the armamentarium of diagnosis and screening. ${ }^{14,15,16,17,18,19}$ Interpretation of the results of genetic testing is complex and requires close cooperation between a patient's sports physician, cardiologist and a genetic expert. Testing results have to be interpreted in the complete context of history, clinical findings, phenotype and potential cardiac risk. Special questions arise with genetic testing in children, where mental health and age should be considered by a specialist for genetic diseases. ${ }^{20,21}$ Genetic testing can provide information which informs lifestyle recommendations with special regards to physical activity. ${ }^{22,23,24,25}$ Recommendations for genetic testing should follow the evidence-based criteria of consensus documents, such as the position statement of the European Society of Cardiology (ESC) working group on genetic counselling and testing in cardiomyopathies; another example is the expert consensus statement on the state of genetic testing for the channelopathies and cardiomyopathies by the Heart Rhythm Society (HRS) and the European Heart Rhythm Association (EHRA). ${ }^{26,27}$

\section{Cardiac diseases with genetic components}

Inherited cardiac diseases with demonstrated underlying genetic causes have been termed "electric" diseases, or channelopathies or ion-channel diseases and cardiac muscular diseases, mainly cardiomyopathies (see Table 1). ${ }^{28,29,30,31}$ This review gives information on some but not all inherited diseases as typical examples.

\section{Epidemiology}

The overall prevalence of inherited cardiac diseases with underlying genetic causes is low, but varies in different countries and among different ethnic groups: Hypertrophic 
cardiomyopathy is approximately 1:500 but higher in African-American men ${ }^{32}$, ARVD is about 1:1000 but with more frequent prevalence in Italy. Ion-Channeldiseases LQT, Brugada Syndrome and, CPVT are each about 1:2000. ${ }^{33,34,35,36,37,38}$

Long-QT-Syndrome (LQT)

LQT-Syndrome can be differentiated into more than eight subtypes according to the underlying chromosomal locus.

Table 2: Examples of some genetic loci ad genes in inherited cardiac disease with normal heart-structure (A: Autosomal, D: Dominant; R: Recessive. RBBB: Right bundle branch block; BrS: Brugada-Syndrome) (modified from Priori \& Zipes $\left.2006^{39}\right)$

\begin{tabular}{|c|c|c|c|c|}
\hline $\begin{array}{l}\text { Locus } \\
\text { Name }\end{array}$ & $\begin{array}{l}\text { Chromosoma } \\
1 \text { Locus }\end{array}$ & $\begin{array}{l}\text { Inheritanc } \\
\mathrm{e}\end{array}$ & Gene Symbol & Phenotype \\
\hline LQT1 & $11 \mathrm{p} 15.5$ & $\mathrm{AD}$ & KCNQ1 & LQT \\
\hline LQT2 & $7 q 35-q 36$ & $\mathrm{AD}$ & $\mathrm{KCNH} 2$ & LQT \\
\hline LQT3 & 3 p21 & $\mathrm{AD}$ & SCN5A & LQT \\
\hline LQT4 & $4 q 25-q 27$ & $\mathrm{AD}$ & ANK2 & LQT, AFib \\
\hline $\mathrm{BrS} 1$ & $3 p 31$ & $\mathrm{AD}$ & SCN5A & ST-Elevation, RBBB \\
\hline BrS2 & $3 p 22-25$ & $\mathrm{AD}$ & $? ? ?$ & “6 \\
\hline CPVT1 & $1 q 42.1-q 43$ & $\mathrm{AD}$ & RyR2 & $\begin{array}{l}\text { Exercise induced } \\
\text { Arrhythmia }\end{array}$ \\
\hline CPVT2 & $1 \mathrm{p} 13.3-\mathrm{p} 11$ & $\mathrm{AR}$ & CASQ2 & \\
\hline ARVD-9 & & $\mathrm{AD}$ & PKP2 & “" \\
\hline ARVD-2 & & $\mathrm{AD}$ & RyR2 & $\begin{array}{l}\text { Plakophilin2, ARVD } \\
\text { Ryanodine-Receptor }\end{array}$ \\
\hline
\end{tabular}

LQT 1, 2 and 3 are of clinical relevance. ${ }^{40,41,42,43,44}$ Diagnosis is based on clinical syndrome, syncopes in history and on typical changes in the resting ECG with prolonged QT-duration. Diagnostic criteria are based on a score system and are shown in Table 3, giving an example how to proceed if the ECG is suspicious. According to score of positive points, diagnosis can be established with low or high probability. 
Table 3: Diagnostic criteria and severity score for LQT-Syndrome (modified from Priori $\&$ Zipes ${ }^{45}$ )

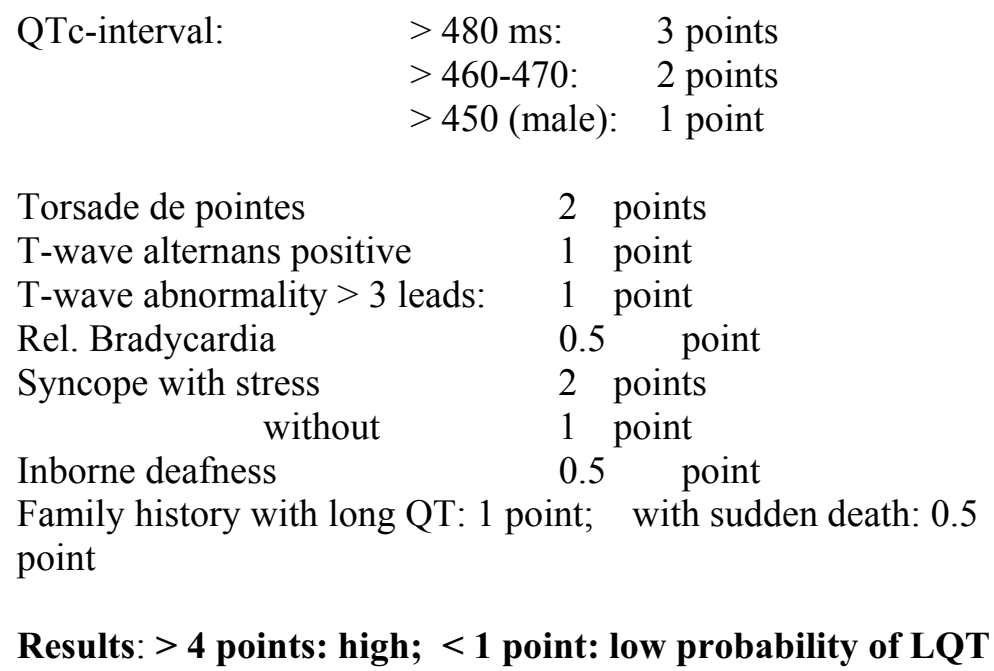

LQT type 1-3 have different but typical triggers provoking arrhythmias, mostly ventricular arrhythmias degenerating into ventricular fibrillation and cardiac arrest. Type 1 (35\%, gene symbol: KCNQ1) is mainly provoked by swimming, diving or exertion. Ackerman et al. ${ }^{46}$ posit that about 30 per cent of drownings in children or adolescents are due to undetected LQT1-syndrome rather than to accident. Arrhythmias in type 2 (about $30 \%$, gene symbol: KCNQH2) can be provoked by auditory triggers. Type 3 (gene symbol SCN5A, 10\%) responds to acute stress or occur spontaneously during sleep. ${ }^{47,48,49,50,51}$ This is known for example from sudden infant death. All drugs prolonging QT-duration should be avoided, and swimming and competitive sport is not recommended for those with LQT1.

Recommendations on genetic testing are shown in Table 7 (below). The Long-QTSyndrome is one entity of the channelopathies which should undergo genetic testing. This may give important prognostic information and indicate therapeutic consequences in the patients as well in family members. ${ }^{52,53,54}$

\section{Short QT-Syndrome}

Short QT-Syndrome with 3 subtypes has been recently reported as another inherited cardiac disease with normal heart appearance (KCNH2, KCNQ1, KCNJ2). Diagnosis is based on ECG recording with short QT-duration and in some patients with typically elevated T-waves. Electrophysiological analysis is strongly recommended, ICD implantation is indicated if VF can be easily provoked. Competitive sports are not recommended. Genetic loci and genes and genetic testing or screening recommendations are given in recent reviews. $55,56,57,58$ 


\section{Brugada-Syndrome}

This syndrome has been described by the Brugada brothers and seems to occur more often than previously assumed. This syndrome appears with a suspicious right bundle branch block (Fig. 1).

Diagnosis is based on provocation with Ajmalin with typical ECG change. ${ }^{59,60,61}$ According to ECG recordings, three modalities have been reported with differing ECG appearance. ${ }^{62}$ In athletes, Brugada syndrome is treated with an ICD after survived sudden death and also with occurrence of complex ventricular arrhythmias. ${ }^{63,64}$ Competitive sports are not recommended. Some drugs, fever or high temperature and electrolyte disturbances should be avoided. ${ }^{65}$ Evidence-based procedure has been reported. ${ }^{66,67,68,69,70}$ Indications for genetic testing in BrugadaSyndrome are shown in Table 7. Due to the high risk of fatal events and possible lethal arrhythmias, detailed examinations are recommended and genetic testing may be generously indicated.

Fig. 1: Young soccer player with multiple syncopes, one with fever which led to the presentation at the emergency department. Suspicious right bundle branch block (above), 25mg of Ajmalin (below) unmasked the typical picture of coved STelevation. Typical Brugada- Syndrome, pt. received an AICD.

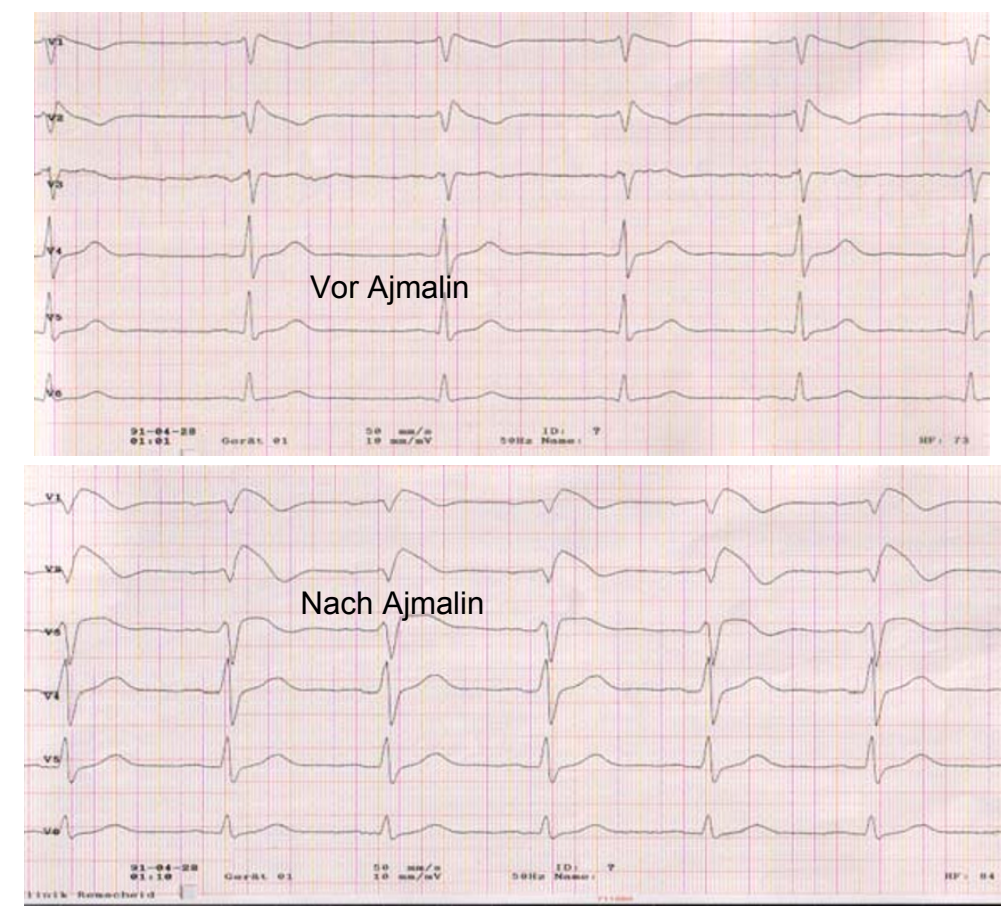

Catecholaminergic polymorphic ventricular tachycardia (CPVT)

CPVT, first described by Coumel $1978,{ }^{71}$ leads to deleterious cardiac events typically during strenuous exercise. Therefore, stress testing for diagnostic purpose should be performed up to real exhaustion thus provoking ventricular arrhythmias. In some cases, emotional stress may also lead to arrhythmias. EPS is negative in most patients. 
Therapy starts with ß-receptor blockers, competitive sports is not allowed, if ventricular arrhythmias do occur. Implantation of an ICD is frequently recommended with ß-blockers to be continued. Recommendations for genetic testing are shown in Table 7.

\section{WPW (Wolff- Parkinson- White -Syndrome or Preexcitation Syndrome)}

Recent studies discuss whether WPW-Syndrome may in part be of genetic origin. ${ }^{72}$ However, at the moment, there is no indication for genetic testing. Diagnostic procedure is standardised. In athletes with frequent episodes of supraventricular tachycardia, EPS is indicated and ablation of the accessory pathway should be considered. The ablation is so far of very low risk and the benefit for the athlete very high. If intermittent atrial fibrillation is present or has been documented, ablation is absolutely indicated as this combination may lead to ventricular fibrillation and sudden cardiac arrest. ${ }^{73,7475,76,77,78}$

\section{Atrial Fibrillation}

Atrial fibrillation has gained a lot of attention as some authors reported a higher frequency of this arrhythmia in endurance athletes or in some former athletes. ${ }^{79,80}$ Two mechanisms are discussed: first, there might be some kind of right ventricular "fatigue" or reduced ejection fraction. On the other hand, there might be so-called vagus induced atrial fibrillation which occurs at night when heart rate drops below 40 $\mathrm{bpm}$, as is present in highly trained endurance athletes. However, there is no unique explanation why this is observed in one athlete and not in others with similar cardiac resting function. ${ }^{81,82}$

As some studies point out that atrial fibrillation is more frequent in some families, an inherited component should be considered. A range of genetic testing has been done; there is no indication for routine gene examination but it may be performed for research purposes in a larger cohort. ${ }^{83}$

\section{Hypertrophic Cardiomyopathy (HCM)}

This disease is the most frequent cause of death among US athletes, especially African-Americans. Similarly, the disease is seen in soccer players from African countries playing for European clubs. Pre-participation examination is mandatory in Europe under FIFA (the international football association) recommendations, including ECG and echocardiography. Athletes with moderate to severe outflow tract obstruction are not allowed to participate in competitive sport. Arrhythmias are secondary to reduced cardiac output in hypertrophic obstructive cardiomyopathy (HOCM) during exercise, with reduced flow through the obstructed left ventricular outflow tract. In the non-obstructed left ventricle, the relative coronary microvascular flow impairment depends on the grade of left ventricular hypertrophy and the intensity of exertion.

Diagnosis of $\mathrm{H}(\mathrm{O}) \mathrm{CM}$ is based on echocardiographic findings. In some athletes, magnetic resonance imaging provides accurate assessment of cardiac structure to confirm (or exclude) hypertrophy of the left ventricle or the interventricular septum. 
Genetic testing is rarely needed in athletes with positive findings (positive phenotype), but may be helpful in borderline structure and in familial examination (see Table 7). Table 4 gives a flow chart for evaluation the subject with HCM and family members. ${ }^{84,85,86,87,88,89,90}$

Table 4: Management and stepwise screening in HCM (modified from Crotti $2001^{91}$ and Ingles $2011^{92}$ )

\begin{tabular}{lll}
\hline Control Symptoms Risk strati & fication & \\
\hline & (Sudden death) & \\
Drug therapy, & Counselling/Screening \\
Pacemaker (?) & Consider ICD if risk & $\begin{array}{l}\text { Physical activity } \\
\text { Septal reduction }\end{array}$ \\
(TASH), HTX & Factors are present & $\begin{array}{l}\text { Practical matters } \\
\end{array}$ \\
& & Genetic counselling \\
\hline
\end{tabular}

Arrythmogenic right ventricular dysplasia or cardiomyopathy (ARVD)

ARVD has a long history. The first description was published by Lancisi in Rome in 1723. ARVD is more prevalent in Italy than in other countries. The diagnostic findings are outlined in Tables 5 and 6 . The diagnostic criteria are differentiated into major and minor signs and symptoms. ${ }^{93}$ These criteria should be strictly analysed, completely and critically, to avoid misdiagnosis. ${ }^{94}$

Table 5: Arrythmogenic right ventricular dysplasia (ARVD): When to look for ARVD?

Two or more signs such as:

- $\quad$ Sustained or non-sustained ventricular tachycardia with left bundle branch type

- $\quad$ Negative. T- wave in lead V1-V3,

- $\quad$ Enlarged right ventricle with contraction abnormality,

- $\quad$ Positive late potentials (SAECG),

- $\quad$ Family history with positive findings (early)

- $\quad$ sudden unexplained death)

- $\quad$ Definite diagnosis is based on minor and major criteria ${ }^{95}$ 
Table 6: $\quad$ Diagnostic procedure in ARVD ${ }^{96}$

Diagnostic criteria are divided in major and minor criteria:

Main findings are :

History: Sudden death in the family

ECG: Disturbed depolarisation and conduction (epsilon-wave)

- Repolarisation abnormalities : negative T-wave)

- Ventricular arrhythmias (VT), PVB

Echo: Global or regional contraction abnormalities of the right ventricle

Biopsy: Fiber-fatty degeneration of the myocardial tissue

Echocardiography and magnetic resonance imaging with typical findings

MRI is a significant method with which to confirm diagnosis, but history, clinical examination, non-invasive imaging (e.g. echocardiography), electrophysiological stimulation (EPS) and myocardial biopsy, if necessary, should be included in the diagnostic procedure. ${ }^{97,98,99,100,101,102,103}$. A new diagnostic test with improved sensitivity has recently been published. ${ }^{104}$ Once the diagnosis is established, competitive sports should be avoided and ICD - implantation has to be considered if necessary. ${ }^{105,106}$ Genetic testing may be carried out for members of the family or if clinical findings are borderline. ${ }^{107,108,109}$

\section{Left ventricular non-compaction cardiomyopathy (NCCM)}

This is a rather rare clinical entity and diagnosis and genetic testing should be performed according to the guidelines and recommendations respectively. Three genes have more commonly been associated: TAZ (Xp28), DTNA and LDB3 with frequent familiar recurrence. ${ }^{110}$

Non-compaction cardiomyopathy often leads to heart failure. Therapy should follow established guidelines. Recommendation on competitive sports depends on the degree of reduced ejection fraction. Genetic testing of patient's relatives is strongly recommended.

\section{Comments on Genetic Testing}

Genetic testing in all patients or athletes is based on an individual cascade screening. In HCM, for example, benefits of genetic testing are to get a "definitive diagnosis and identification of at-risk family members", 111 confirmation of diagnosis and genetic cause of hypertrophy and, in terms of research, to "gain greater understanding of fundamental disease biology". ${ }^{112}$ The limitations of genetic testing should be considered, including: clinical yield non-informative results, mutation not identified, limited clinical impact and ambiguous results (modified from Ho $2012^{113}$ ). Results of genetic testing are probabilistic rather than quantitative. ${ }^{114}$ 
The position statement of the ESC refers to some key messages (modified from Crotti $\left.2010^{115}\right)$ :

- Genetic origin of e.g. cardiomyopathy

- Mode of inheritance, risk of transmission

- Clinical manifestation, natural history

- Benefits of screening within the family

- Risk of worsening during pregnancy

- Availability and scope of molecular/genetic testing

- Appropriate patient organisation

- Medical sources of organisation

- Information about the referral centre

Information about all of these should be given during genetic counselling. The protocol of this counselling should contain: the name of the person who receives the counselling, time of counselling, results of genetic testing and predictive diagnosis which have been given to the patient (athlete) (see position statement ${ }^{116,117}$ ). The key messages clearly demonstrate that consultation with a trained professional with expert knowledge is needed by each individual. The social background also has to be taken into consideration as the consequences for each family member are considerable.

\section{Risk stratification}

There is an increasing interest in the risks and benefit of regular and intense physical activity or competitive sports. ${ }^{118,119,120,121,122,123,124,125,126,127}$ Certain registers collate the frequency of and association with type of sport of fatal events. ${ }^{128}$ Pre-participation examination is under discussion, as is whether or not resting ECG should be included. There are some findings indicating that examination with ECG may reduce sudden death in sport. ${ }^{129}$ One research study in Germany clearly showed that many participants in long distance running had not undergone medical examination before taking up the sport. ${ }^{130}$

Many factors favour cardiac complications during physical activity. ${ }^{131}$ Bursts of exertion, adverse environmental conditions (heat, cold), prolonged endurance in activities such as triathlon or marathon, electrolyte disturbances, stress, in some kinds of sports (such as hang gliding or bungee jumping), acute or chronic drug abuse (including doping), and finishing with higher intensity all predispose to adrenergic stimulation, thus enhancing pro-arrhythmogenic effects.

A number of deaths during exercise or in athletes have been associated with genetic cardiovascular disease. These genetic components together with above mentioned factors are responsible for a substantial proportion of unexpected cardiac events and deaths during adolescence and young adulthood. ${ }^{132,133,134}$ Pre-participation examination, including resting ECG, is strongly recommended, as is the continuing education of sports physicians and cardiologists about inherited diseases, and this will be offered in Europe in the near future. 


\section{Professional qualification and cooperation with specialists}

Exercise testing in older sportspeople should be performed according to existing guidelines. Nonetheless, the physician performing the examination should be aware of inherited diseases; (s)he should be trained as a sports cardiologist with special training in ECG interpretation. The physician or sports cardiologist should closely cooperate with genetic diagnostics and diseases specialists. Genetic testing too should follow the recommendations. ${ }^{135}$

As diagnostic tests become cheaper, insurance companies should in the future pay for genetic diagnosis (in accordance with guidelines) in order to prevent complications in young people and especially in genetically disposed families. Negative results in genetic testing do not exclude established clinical diagnosis as test results have a sensitivity ranging between $26-70$ per cent. ${ }^{136}$ Detected mutations should be considered in tandem with the clinical findings.

Finally, in the case of sudden unexplained death in the context of sport or physical exertion, molecular autopsy should be a standard to evaluate for a definitive diagnosis, and not only for research purposes. ${ }^{137}$ This procedure gives reliable results for family members and findings which could help other sportswomen and sportsmen in the future.

\section{Conclusion}

At present, genetic screening is recommended to protect the athlete from cardiac risks if the diagnostic findings are borderline. If the clinical diagnosis is unequivocal, testing may only be useful for family members or appropriate relatives. Clinical examination must be the first step with treatment of symptoms, if present. Risk stratification of complications such as cardiac arrest is the next step, according to numbers of risk factors, followed by lifestyle and physical activity recommendations. Family screening should be performed according to the guidelines to prevent fatal events in relatives and genetic experts should be involved. Existing recommendations and guidelines support this basic procedure in these examinations. ${ }^{138,139,140,141}$ 
Table 7: Recommendations for Genetic Testing in Cardiac Genetic Diseases (Extract modified from existing guidelines ${ }^{142}$ )

\section{STATE OF GENETIC TESTING FOR LONG QT SYNDROME (LQTS)}

Class I (is recommended)

Comprehensive or LQT1-3 (KCNQ1, KCNH2, and SCN5A) targeted LQTS genetic testing is recommended for any patient in whom a cardiologist has established a strong clinical index of suspicion for LQTS based on examination of the patient's clinical history, family history, and expressed electrocardiographic phenotype (resting 12-lead ECG and/or provocative stress testing with exercise or catecholamine infusion).

Comprehensive or LQT1-3 (KCNQ1, KCNH2, and SCN5A) targeted LQTS genetic testing is recommended for any asymptomatic patient with QT prolongation in the absence of other clinical conditions that might prolong the QT interval (such as electrolyte abnormalities, hypertrophy, bundle branch block, etc., i.e., otherwise idiopathic) on serial 12-lead ECG defined as QTc.480 ms (prepuberty) or $0.500 \mathrm{~ms}$ (adults).

Mutation-specific genetic testing is recommended for family members and other appropriate relatives subsequently following the identification of the LQTS-causative mutation in an index case.

Class IIb (may be considered)

Comprehensive or LQT1-3 (KCNQ1, KCNH2, and SCN5A) targeted LQTS genetic testing may be considered for any asymptomatic patient with otherwise idiopathic QTc values .460 $\mathrm{ms}$ (prepuberty) or .480 ms (adults) on serial 12-lead ECG.

\section{STATE OF GENETIC TESTING FOR CATECHOLAMINERGIC POLYMORPHIC VENTRICULAR TACHYCARDIA (CPVT) \\ Class I (is recommended) \\ Comprehensive or CPVT1 and CVPT2 (RYR2 and CASQ2) targeted CPVT genetic testing is recommended for any patient in whom a cardiologist has established a clinical index of suspicion for CPVT based on examination of the patient's clinical history, family history, and expressed electrocardiographic phenotype during provocative stress testing with cycle, treadmill, or catecholamine infusion. \\ Mutation-specific genetic testing is recommended for family members and appropriate relatives following the identification of the CPVT-causative mutation in an index case.}

\section{STATE OF GENETIC TESTING FOR BRUGADA SYNDROME (BrS)}

Class I (is recommended)

Mutation-specific genetic testing is recommended for family members and appropriate relatives following the identification of the BrS-causative mutation in an index case.

Class IIa (can be useful)

Comprehensive or BrS1 (SCN5A) targeted BrS genetic testing can be useful for any patient in whom a cardiologist has established a clinical index of suspicion for $\mathrm{BrS}$ based on examination of the patient's clinical history, family history, and expressed electrocardiographic (resting 12-lead ECG and/or provocative drug challenge testing) phenotype.

Class III (is not indicated/recommended)

Genetic testing is not indicated in the setting of an isolated type 2 or type 3 Brugada ECG pattern.

\section{STATE OF GENETIC TESTING FOR HYPERTROPHIC CARDIOMYOPATHY (HCM) \\ Class I (is recommended)}


Comprehensive or targeted (MYBPC3, MYH7, TNNI3, TNNT2, TPM1) HCM genetic testing is recommended for any patient in whom a cardiologist has established a clinical diagnosis of HCM based on examination of the patient's clinical history, family history, and electrocardiographic/echocardiographic phenotype.

Mutation-specific genetic testing is recommended for family members and appropriate relatives following the identification of the HCM-causative mutation in an index case.

\section{STATE OF GENETIC TESTING FOR ARRHYTHMOGENIC \\ CARDIOMYOPATHY (ACM) ARRHYTHMOGENIC RIGHT VENTRICULAR CARDIOMYOPATHY (ARVC)}

Class I (is recommended)

Mutation-specific genetic testing is recommended for family members and appropriate relatives following the identification of the ACM/ARVC causative mutation in an index case.

Class IIa (can be useful)

Comprehensive or targeted (DSC2, DSG2, DSP, JUP, PKP2, and TMEM43) ACM/ARVC genetic testing can be useful for patients satisfying task force diagnostic criteria for $\mathrm{ACM} / \mathrm{ARVC}$.

Class IIb (may be considered)

Genetic testing may be considered for patients with possible ACM/ARVC (1 major or 2 minor criteria) according to the 2010 task force criteria (European Heart Journal).

Class III (is not indicated/recommended)

Genetic testing is not recommended for patients with only a single minor criterion according to the 2010 task force criteria.

\section{STATE OF POST-MORTEM GENETIC TESTING IN SUDDEN UNEXPECTED DEATH CASES (SUD/SIDS)}

Class I (is recommended)

For all SUDS and SIDS cases, collection of a tissue sample is recommended (5-10 mL whole blood in EDTA tube, blood spot card, or a frozen sample of heart, liver, or spleen) for subsequent DNA analysis/genetic testing.

Mutation-specific genetic testing is recommended for family members and other appropriate relatives following the identification of a SUDS causative mutation in the decedent.

Class IIb (may be considered)

In the setting of autopsy negative SUDS, comprehensive or targeted (RYR2, KCNQ1, $\mathrm{KCNH} 2$, and SCN5A) ion channel genetic testing may be considered in an attempt to establish probable cause and manner of death and to facilitate the identification of potentially at-risk relatives and is recommended if circumstantial evidence points toward a clinical diagnosis of LQTS or CPVT specifically (such as emotional stress, acoustic trigger, drowning as the trigger of death.

\footnotetext{
${ }^{1}$ German Federation of Sports Medicine, and Cardiology Practice, Remscheid; The Children's Hospital at Westmead, Sydney, Australia. herbert.loellgen@gmx.de

${ }^{2}$ H. Löllgen, A. Böckenhoff and G. Knapp: Primary prevention by physical activity: an updated metaanalysis with different intensity categories. Int J Sports Med 2009; 30: 213-224.

${ }^{3}$ V. F. Froehlicher and J. Myers. 2006. Exercise and the heart 5th ed. Philadelphia. Saunders.

${ }^{4}$ H. Löllgen, D. Leyk and J. Hansel. The pre-participation examination for leisure time physical activity. Dtsch Ärztebl Int 2010; 107: 742-749.
} 


\footnotetext{
${ }^{5} \mathrm{~S}$. v. Klot et al. Intensity of physical exertion and triggering of myocardial infarction: a case-crossover study. Europ H J 2008; 29: 1881-1888.

${ }^{6}$ M. A. Mittleman and E. Mostofsky. Physical, psychological and chemical triggers of acute cardiovascular events. Circulation 2011; 124: 346-354.

${ }^{7}$ B. J. Maron et al. Sudden death in young competitive Athletes. Circulation 2009; 119: 1085-1092.

${ }^{8}$ Froehlicher and Myers, op. cit. note 3.

${ }^{9}$ L. Crotti. Genetic predisposition to sudden cardiac death. Curr Opin Cardiol 2001; 26: 46-50.

${ }^{10}$ S. G. Priori and D. P. Zipes. 2006. Sudden cardiac death. Malden, MA. Blackwell.

${ }^{11}$ Ibid.

12 J. Beckermann et al. Exercise test-induced arrhythmias. Progr Cardiovasc Dis 2005; 47: 285-305.

${ }^{13}$ B. R. Chaitman. 2007. Exercise stress testing. In Braunwald's Heart Disease $8^{\text {th }}$ ed. P. Libby, L. P. Bonow, R. O. Mann and D. L. Zipes, eds. Philadelphia. Saunders: 195-226.

${ }^{14}$ Priori and Zipes, op. cit. note 10.

${ }^{15}$ M. Ackerman et al. HRS/EHRA expert consensus statement on the state of genetic testing for channelopathies and cardiomyopathies. Europace 2011; 13: 1077-1109.

${ }^{16} \mathrm{P}$. Charron et al. Genetic counselling and testing in cardiomyopathies: A position statement of the European society of cardiology working group on myocardial and pericardial diseases. Europ Heart J 2010; 31: 2715-2728.

17 J. Ingles et al. Guidelines for genetic testing of inherited cardiac disorders. Heart, Lung, Circulation 2011; 20: 681-687.

18 A. Pellicia, D. P. Zipes and B. J. Maron. Bethesda conference \#36 and the European society of cardiology consensus recommendations revisited. J Am Coll Cardiol 2008; 52: 1990-1996.

19 J. Vohra, J. Skinner, C. Semsarian. Cardiac genetic investigation in young sudden unexplained death and resuscitated out of hospital cardiac arrest. Heart, Lung, Circulation 2011; 20: 746-750.

${ }^{20}$ Charron et al., op. cit. note 16, pp. 2715-2728.

${ }^{21}$ Ingles et al., op. cit. note 17, pp. 681-687.

${ }^{22}$ Ibid.

${ }^{23}$ Charron et al., op. cit. note 16, pp. 2715-2728.

24 Ingles et al., op. cit. note 17, pp. 681-687.

${ }^{25}$ F.I.Marcus, M. McKenna and D. Sherill: Diagnosis of arrhythmogenic right ventricular cardiomyopathy/ dysplasia. Europ Heart J 2010; 31: 806-814.

${ }^{26}$ Ackerman et al., op. cit. note 15, pp. 1077-1109.

${ }^{27}$ Charron et al., op. cit. note 16, pp. 2715-2728.

${ }^{28}$ Ackerman et al., op. cit. note 15, pp. 1077-1109.

${ }^{29}$ A. Asimaki et al. A new diagnostic test for arrhythmogenic right ventricular cardiomyopathy. NEJM 2009; 360: 1075 -1084.

${ }^{30}$ B. M. Beckmann, A. Pfeufer and S. Kääb. Inherited cardiac arrhythmias: diagnosis, treatment and prevention. Dtsch Ärztebl int 2011; 108: 623-634.

${ }^{31} \mathrm{~S}$. Kauferstein et al. Cardiac gene defects can cause sudden cardiac death in young people. Dtsch Arztebl int 2009; 106: 41-47.

${ }^{32}$ F. M. Di Paolo et al. The athlete's heart in adolescent Africans. JACC 2012; 59: 1029-1036.

${ }^{33}$ Charron et al., op. cit. note 16 , pp. 2715-2728.

${ }^{34}$ Ingles et al., op. cit. note 17, pp. 681-687.

${ }^{35}$ Beckmann et al., op. cit. note 30, pp. 623-634.

${ }^{36}$ C. Y. Ho: Hypertrophic cardiomyopathy in 2012. Circulation 2012; 125: 1432-1438.

${ }^{37}$ B. J. Maron and D. P. Zipes: $36^{\text {th }}$ Bethesda Conference: Eligibility recommendations for competitive athletes with cardiovascular abnormalities. JACC 2005; 45: 1313-1375.

${ }^{38}$ B. J. Maron, B. R. Chaitman and M. J. Ackerman. Recommendations for physical activity and recreational sports participation for young patients with genetic cardiovascular diseases. Circulation 2004; 109: 2807-2816.

${ }^{39}$ Priori and Zipes, op. cit. note 10.

${ }^{40}$ Ibid.
} 
${ }^{41}$ Ingles et al., op. cit. note 17, pp. 681-687.

${ }^{42}$ Kauferstein, et al., op. cit. note 31, pp. 41-47.

${ }^{43}$ Maron and Zipes, op. cit. note 37, pp. 1313-1375.

${ }^{44}$ E. A. Stephenson and C. I. Berul. Electrophysiological interventions for inherited arrhythmia syndromes. Circulation 2007; 116: 1062-1080.

${ }^{45}$ Ibid.

${ }^{46}$ Ackerman et al., op. cit. note 15, pp. 1077-1109.

${ }^{47}$ Priori and Zipes, op. cit. note 10.

${ }^{48}$ Ackerman et al., op. cit. note 15, pp. 1077-1109.

${ }^{49}$ Beckmann et al., op. cit. note 30, pp. 623-634.

${ }^{50}$ Kauferstein et al., op. cit. note 31, pp. 41-47.

${ }^{51}$ J. Vohra: Diagnosis and management of Brugada syndrome. Heart, Lung, Circulation 2011; 20: 751775 .

${ }^{52}$ Charron et al., op. cit. note 16, pp. 2715-2728.

${ }^{53}$ Beckmann et al., op. cit. note 30, pp. 623-634.

${ }_{55}^{54}$ Stephenson and Berul, op. cit. note 44, pp. 1062-1080.

${ }^{55}$ Priori and Zipes, op. cit. note 10.

${ }^{56}$ Ackerman et al., op. cit. note 15, pp. 1077-1109.

${ }^{57}$ Charron et al., op. cit. note 16, pp. 2715-2728.

${ }^{58}$ Ingles et al., op. cit. note 17, pp. 681-687.

${ }^{59}$ Priori and Zipes, op. cit. note 10.

${ }^{60}$ Vohra, op. cit. note 51, pp. 746-750.

${ }^{61}$ R. Lemery et al. Non-ischemic ventricular tachycardia: clinical course and long-term follow-up in patients without clinically overt heart disease. Circulation 1989; 79: 990-999.

${ }^{62}$ Ackerman et al., op. cit. note 15, pp. 1077-1109.

${ }^{63}$ Stephenson and Berul, op. cit. note 44, pp. 1062-1080.

${ }^{64} \mathrm{H}$. Löllgen, H. Wollschläger and G. Schönrich. Ventricular arrhythmias and QTc interval during stress - ECG. Herz/Heart 1986; 11: 303-308.

${ }^{65}$ Ibid.

${ }^{66}$ Mittleman and Mostofsky, op. cit. note 6, pp. 346-354.

${ }^{67}$ Vohra, op. cit. note 51, pp. 746-750.

${ }^{68}$ Marcus et al., op. cit. note 25, pp. 806-814.

${ }^{69}$ Beckmann et al., op. cit. note 30, pp. 623-634.

${ }^{70}$ Maron et al., op. cit. note 38, pp. 2807-2816.

${ }^{71}$ Coumel P, et al.: Catecholaminergic-induced severe ventricular arrhythmias with Adams-Stokes syndrome in children:report of four cases. Br Heart J 1978:40:28-37

${ }^{72}$ Santinelli V. et al. :The natural history of asymptomatic ventricular pre-excitation: A long-term prospective follow-up study of 184 asymptomatic children. J Am Coll Cardiol 2009, 20:275-280.

${ }^{73}$ Priori and Zipes, op. cit. note 10.

${ }^{75}$ Pellicia et al., op. cit. note 18, pp. 1990-1996.

${ }^{75}$ Maron and Zipes, op. cit. note 37, pp. 1313-1375.

${ }^{76}$ Maron et al., op. cit. note 38, pp. 2807-2816.

${ }^{77}$ Stephenson and Berul, op. cit. note 44, pp. 1062-1080.

${ }^{78} \mathrm{~V}$. Santinelli et al. The natural history of asymptomatic ventricular pre-excitation: A long-term prospective follow-up study of 184 asymptomatic children. J Am Coll Cardiol 2009; 20: 275-280.

${ }^{79}$ Priori and Zipes, op. cit. note 10.

${ }^{80} \mathrm{~A}$. LaGerche et al. Exercise - induced right ventricular dysfunction and structural remodelling in endurance athletes. Euro Heart J 2012; 33: 998-1006.

${ }^{81}$ Froehlicher and Myers, op. cit. note 3.

${ }^{82}$ LaGerche et al., op. cit. note 80, pp. 998-1006.

${ }^{83}$ Stephenson and Berul, op. cit. note 44, pp. 1062-1080.

${ }^{84}$ Crotti, op. cit. note 9, pp. 46-50.

${ }^{85}$ Beckmann et al., op. cit. note 30, pp. 623-634.

${ }^{86}$ Maron and Zipes, op. cit. note 37, pp. 1313-1375. 
${ }^{87}$ Maron et al., op. cit. note 38, pp. 2807-2816.

${ }^{88}$ Stephenson and Berul, op. cit. note 44, pp. 1062-1080.

${ }^{89}$ LaGerche et al., op. cit. note 80, pp. 998-1006.

${ }^{90}$ A. P. Morise: Exercise testing in nonatherosclerotic heart disease. Circulation 2011; 123: 216-225.

${ }^{91}$ Crotti, op. cit. note 9, pp. 46-50.

${ }^{92}$ Ingles et al., op. cit. note 17, pp. 681-687.

${ }^{93}$ Marcus et al., op. cit. note 25, pp. 806-814.

${ }^{94} \mathrm{C}$. Bomma et al. Misdiagnosis of arrhythmogenic right ventricular dysplasia/cardiomyopathy. $J$

Cardiovasc Electrophysiol 2004; 15: 300-306.

${ }_{95}^{95}$ Maron and Zipes, op. cit. note 37, pp. 1313-1375.

${ }^{96}$ Marcus et al., op. cit. note 25, pp. 806-814.

${ }^{97}$ Priori and Zipes, op. cit. note 10.

${ }^{98}$ Ingles et al., op. cit. note 17, pp. 681-687.

${ }^{99}$ Marcus et al., op. cit. note 25, pp. 806-814.

${ }^{100}$ Beckmann et al., op. cit. note 30, pp. 623-634.

${ }^{101}$ Kauferstein, et al., op. cit. note 31, pp. 41-47.

${ }^{102}$ LaGerche et al., op. cit. note 80, pp. 998-1006.

${ }^{103} \mathrm{~W}$. Smith. Guidelines for the diagnosis and management of arrhythmogenic right ventricular cardiomyopathy. Heart,Lung Circulation 2011; 20: 757-760.

${ }^{104}$ Asimaki op. cit. note 29, pp. 1075-1084.

${ }^{105}$ Ho, op. cit. note 36, pp. 1432-1438.

${ }^{106}$ Stephenson and Berul, op. cit. note 44, pp. 1062-1080.

${ }^{107}$ Ackerman et al., op. cit. note 15, pp. 1077-1109.

${ }^{108}$ Charron et al., op. cit. note 16, pp. 2715-2728.

${ }^{109}$ Ingles et al., op. cit. note 17, pp. 681-687.

${ }^{110} \mathrm{R}$. Löllgen. Recent onset of cardiac failure due to non-compaction cardiomyopathy in children.

In preparation. 2013.

${ }^{111}$ Ho, op. cit. note 36 , pp. 1432-1438.

${ }^{112}$ Ibid.

${ }^{113}$ Ibid.

${ }^{114}$ Charron et al., op. cit. note 16, pp. 2715-2728.

${ }^{115}$ Crotti, op. cit. note 9, pp. 46-50.

${ }^{116}$ Ackerman et al., op. cit. note 15, pp. 1077-1109.

${ }^{117}$ Charron et al., op. cit. note 16, pp. 2715-2728.

${ }^{118}$ Mittleman and Mostofsky, op. cit. note 6, pp. 346-354.

${ }^{119}$ Priori and Zipes, op. cit. note 10.

${ }^{120}$ Beckermann et al., op. cit. note 12, pp. 285-305.

${ }^{121}$ Pellicia et al., op. cit. note 18, pp. 1990-1996.

${ }^{122}$ Beckmann et al., op. cit. note 30, pp. 623-634.

${ }^{123}$ Kauferstein et al., op. cit. note 31, pp. 41-47.

${ }^{124}$ Di Paolo et al., op. cit. note 32, pp. 1029-1036.

${ }^{125}$ Maron and Zipes, op. cit. note 37, pp. 1313-1375.

${ }^{126}$ Maron et al., op. cit. note 38, pp. 2807-2816.

${ }^{127}$ Morise, op. cit. note 90, pp. 216-225.

${ }^{128}$ Mittleman and Mostofsky, op. cit. note 6, pp. 346-354.

${ }^{129}$ Pellicia et al., op. cit. note 18, pp. 1990-1996.

${ }^{130}$ D. Leyk et al. Utilization and implementation of sports medical screening examination - Survey of more than 10000 long distance runners. Dtsch Ärztebl int 2008; 105: 609-614.

${ }^{131}$ Maron et al., op. cit. note 38, pp. 2807-2816.

${ }^{132}$ Maron et al., op. cit. note 7, pp. 1085-1092.

${ }^{133}$ Maron and Zipes, op. cit. note 37, pp. 1313-1375.

${ }^{134}$ Maron et al., op. cit. note 38, pp. 2807-2816.

${ }^{135}$ Ackerman et al., op. cit. note 15, pp. 1077-1109.

${ }^{136}$ Beckmann et al., op. cit. note 30, pp. 623-634. 
${ }^{137}$ Kauferstein, et al., op. cit. note 31, pp. 41-47.

${ }^{138}$ Ackerman et al., op. cit. note 15, pp. 1077-1109.

${ }^{139}$ Charron et al., op. cit. note 16, pp. 2715-2728.

${ }^{140}$ Ingles et al., op. cit. note 17, pp. 681-687.

${ }^{141}$ Ho, op. cit. note 36, pp. 1432-1438.

${ }^{142}$ Ackerman et al., op. cit. note 15, pp. 1077-1109. 